\title{
Encounters with Efficacy
}

\author{
Vincanne Adams
}

Basham Medal Essay

Note: The Basham Medal commemorates the name of Professor Arthur L. Basham, co-founder of the International Association for the Study of Traditional Asian Medicine (IASTAM), and is given "to recognize special contributions by IASTAM members to promoting the goals of IASTAM". In 2009 it was awarded at the International Conference on Tradition Asian Medicine in Thimphu, Bhutan to Professor Vincanne Adams, of the Department of Anthropology, History and Social Medicine of the University of California, San Francisco. This is the paper she delivered on that occasion.

Vincanne's research interests include the social conditions and epistemological framings of integrative medicine, international health development, women's health and health care in Tibet, theories of modernity in relation to morality, disaster capitalism, aging and displacement politics. Her primary research area has been the Himalayan region (Nepal and Tibet), where she has worked on topics such as medical pluralism, medicine and social change, and the politics of clinical trials research. More recently, she has also studied life disruption and disaster as a way of life in post-Katrina New Orleans. Vincanne is also interested in global studies of science, technology and medicine, and particularly the postcolonial exchange of scientific activities (from labs to field sites, informed consent procedures to the residual problem of spirit-caused disorders). Her works include Doctors for Democracy: Health Professionals in the Nepal Revolution (1998), Tigers of the Snow and Other Virtual Sherpas: an Ethnography of Himalayan Encounters (1996), Sex in Development: Science, Sexuality, and Morality in Global Perspective (2005, with Stacy Leigh Pigg) and Medicine between Science and Religion: Explorations on Tibetan Grounds (2011, with Mona Schrempf and Sienna R. Craig). Vincanne's work speaks to both academics and practitioners of traditional Asian medicine, in a way that is consistently inspiring, intellectually incisive, and topical in the issues that it addresses.

\section{Keywords}

efficacy, Asian medicine, Tibetan medicine, soul loss, healing, GMP

I'm honoured to receive the Basham Medal, and want to thank the IASTAM selection committee for this recognition, and I'd also like to thank the IASTAM organizers and the Bhutanese government for hosting the ICTAM VI conference. I want to dedicate this talk to Charles Leslie, who was inspired by Basham in his own work, and who tirelessly and with absolute optimism worked to build IASTAM as an intellectual space for us all to come together. ${ }^{1}$

${ }^{1}$ Charles Leslie encouraged and mentored me in publishing my first article in the field of medical anthropology (in Social Science and Medicine) while I was in graduate school. 
Charles, more than most others in his time, believed in a comprehensive approach to study of Asian medicines, and particularly of understanding synecdoche - the idea that the part can stand for the whole-when it comes to studying medicine. ${ }^{2} \mathrm{He}$ showed us how the most detailed diagnostic conundrum of the Vaidya could also simultaneously reveal much about the larger place of Ayurveda in contemporary India. His recent passing calls as a reminder to what not only great passion but also great commitment to the most particular ethnographic detail can accomplish.

This familiar territory is the focus and inspiration for my own work on the topic of efficacy. By efficacy I mean, at least at this starting point, quite simply, the idea that a medicine or intervention works. What I'd like to do in the remainder of this presentation is to walk through some of the more interesting "encounters with efficacy" that I've had over the past thirty years in order to ask how might we sustain a platform for inquiry that situates the problem of efficacy in the broadest possible terms, and in a manner that encompasses the way in which the part (the most intimate of clinical engagements) also stands for the whole (the place of Asian Medicine in the modern world). I situate this effort in the contemporary framework of studies in post-colonial technoscience, exploring efficacy as an empirical problem just as much for the shaman as for the pharmaceutical scientist, and as an endeavour that can contribute social science insights to an understanding of how best to heal. ${ }^{3}$

I begin with a somewhat personal anecdote. Some years ago, I was invited to join a group of Tibetan and American doctors and nurses in developing a training program for safe motherhood for rural health workers in and around the Lhasa prefecture. The group I worked with was based in Utah, and at one point, several years into the project, one woman on the team, Diana, helped orchestrate a visit and series of lectures there by $\mathrm{HH}$ the Dalai Lama, who was collectively and affectionately known to those of us who worked in the Tibetan Autonomous Region by the code name "Bruce." Bruce was from "Hoboken" (code for Dharamsala).

\footnotetext{
${ }^{2}$ Judith Farquhar also used this concept to understand the role of socialist politics in modernizing Chinese Medicine (1987).

${ }^{3}$ I also want to acknowledge two close colleagues with whom I have worked and been inspired by over the past 10 to 15 years Dr. Renchen Dhondup and Dr. Sienna Craig. I also acknowledge support from the NSF, NIH (NICHD), Wenner Gren Foundation, UCSF REAC, for generous support at different times over the past years for different aspects of the work that led to the analysis in this paper. Other colleagues I am grateful to have worked with on these projects in Tibet include: Drs. Nyima Lhamo, Lhakpen, Mingkyi Tsomo, Yangdron Kelsang, and Phuoc V. Le, Fei Fei Li, Arlene Samen, Michael Varner and Suellen Miller. I have used pseudonyms for all of the persons (other than cited scholars) in this presentation.
} 
Recognizing the importance of the event, and the opportunity for our team to meet with Bruce and receive his advice, we all bought tickets and the organizer made a request for a private audience during his visit. Months passed and although I knew I would be able to go to the talks, I was not sure of the time of our audience. I went ahead and scheduled my plane flights-a task that was complicated by the fact that that weekend was Mother's Day and the birthday of my nine-year-old daughter, whose party was scheduled for that Sunday. I strategically planned the trip so that I would arrive Thursday evening, plenty of time for the Friday and Saturday lectures, surely for an audience, and then be able to fly home late Saturday night to get home in time for the birthday party!

All was fine until I got the call one week before our audience from Diana telling me that our audience was scheduled for Sunday, probably in the morning." "Oh no!" I said, "I won't be able to come. I explained about the birthday party, Mother's Day, my nine year old. She paused, then scolded me: "Vincanne, this is a once in a lifetime opportunity. You can't miss this". I hung up, called the airline and figured out that with the time change, I could probably get a flight on Sunday morning at noon and be home only an hour late for the birthday party. When I told my daughter about this, she looked disappointed. Then, sternly, she said, "Mom, when you meet the Dalai Lama, you just ask him: 'Could you please hurry things up so I can get home to my daughter's birthday party?”. I laughed, appreciating her willingness to accommodate me.

A few days later, Diana and I sat, fourth row in the centre, for the first of Bruce's lectures on the Perfection of Wisdom. About 45 minutes in, Diana was hailed from behind the stage by one of the Tibetan staff and she scurried off. Bruce had just made a complicated point about the substitutability of things like time when viewed from the framework of non-attachment, cessation of desire. Days of the week could be interchangeable, or months, or even years..., he said. I was trying to concentrate, but my mind was already far off the perfections, meandering to our upcoming audience. "I'd better think about what I want to say," I thought, "because I'll probably only have a few minutes to speak with him directly". At that instant, of course, my daughter's voice came into my head: "You ask him: Could you please hurry things up so that I can get home to my daughter's birthday party?".

I looked up and Bruce was looking directly at me, smiling. My Sherpa friends once told me that getting a blessing from a high lama was like having a peacock feather open up on your head. I knew what they meant. It was just a smile, but it felt like he was smiling at what my daughter had said. And then, he looked away. He went on to make his next point, heading toward 
perfection. I sat there in the moments afterward, feeling special that I'd made eye contact, when Diana came back to her seat, leaned over to me, and said: "Our audience just got moved up to Saturday afternoon!".

Coincidence? Probably. But it didn't feel that way. It felt like something else. It felt like it was one of those rare moments of witnessing - a moment of recognition of the possibility that there were some unfathomable chains of cause and effect that I simply could not understand, but had to take on faith because of the evidence at hand.

By the time we made our way to our audience at the Governor's mansion on Saturday afternoon, we had expanded our numbers to include a close friend of Diana, Rosemary. Rosemary had been losing her three-year fight against breast cancer. We gathered in the living room, and within minutes Bruce swooped in and took his seat near the window. He asked and we told him about our project and he said it is very important to take care of the women, especially the rural women. It felt unsatisfying in some ways. I'd put all this effort into meeting him and that was it - just a nod of affirmation that what we were doing was good. No deep or transcendent insights about our higher purpose, no pearls of spiritual wisdom about our mission.... Instead, he turned his attention to Rosemary. He asked about her bald head. He said she looked like a nun, and she explained that she had cancer. He asked more. She had 3 young children. She was a nurse. The treatments were difficult. It was breast cancer but it had spread. Then, he stood up to leave, and the rush of other visitors waiting in the hallway for press photos began to push us out of the way. Just as we were entering the hallway, though, he turned back to us and walked directly to Rosemary. He took her two hands and raised them to chest height. Her white blessing scarf, her khada, clenched in their shared grasp, he leaned forward and placed his forehead onto hers.

I don't know how long his prayers lasted, but when it was over we were all sort of shaky. I had a feeling of emotional surfeit, like it was all just too much for the brain, or more important, the heart to hold. We held Rosemary's arms to walk out of the room-and Bruce was whisked off by his handlers. All Rosemary could say was "What just happened? What just happened?". Tears streamed down her face. She was smiling. She cried. We all cried. We held onto her, trying to help her decipher the moment. We couldn't. We were all a mess. She held Diana's hand tightly. She said that it was as if she had "gone somewhere else" for a moment. It was as if it didn't matter, for a moment, that she was dying.

It dawned on me then that our meeting with Bruce, despite my certainty of it being important for me, or for our work, was not about me or even our work at all. Our concerns about the meeting were somewhat incidental to 
what had actually happened. But Rosemary had a chance to meet with and get something very meaningful from Bruce.

Sometimes we "moderns" get a momentary glimpse into a world that makes sense only if we keep our eyes squinted and head cocked, suspending disbelief until eventually giving in to the possibility that we can't really understand the reasons behind the unfolding of events. There are things beyond us, things that happen for reasons that our modern reasoning minds are not entirely prepared to explain. They make sense, but only because we allow ourselves to read them sideways, not head on, only because we make sense of them in our heart, not in our brains. I suspect that this is also a productive way to think about efficacy. That is, when it comes to questions of efficacy, it sometimes helps to read between the lines, to recognize the things that don't make immediate or rational sense, that are not easily explained by the logics of reason and sense that some of us children of the Enlightenment are most comfortable with.

As I revisited some of the histories of IASTAM, the edited volumes it has produced and the empirical and epistemological conundrums it has addressed, I realized that many of these volumes had provided an opportunity for an open discussion of just these concerns. They asked us to embrace and make a different kind of sense of phemonema that were easily dismissed by scientific observers. Some things could only be made sensible through technically complex acts of translation between incommensurable worlds, by thinking through the lens of different sorts of rationalities. They often required the act of suspending disbelief-having some sort of faith in miraculous cures and magical healing, of invisible causes and tangible effects, despite their obvious departure from explanations that made one kind of sense.

It was actually articles like Basham's lead article in the now classic Asian Medical Systems, edited by Charles Leslie, which first kindled my interest in Asian Medicine. ${ }^{4}$ Basham wrote about a time of great medical flourishing in Ancient India-when doctors were motivated by their compassion and skill and quacks were kept out, when wayside rest-stops had skilled physicians available to the weary and sick traveler, when cures were witnessed by or for royalty who rewarded these healers well. Ancient and medieval India had rudimentary hospitals_-medical halls-with practitioners skilled in complex compounding techniques for treating all sorts of diseases, even performing surgeries. Across the canons of Buddhist and Hindu healing, apprentices were sent on missions to find any substances that had no medicinal value only to realize that this was impossible. Everything consumable, crushable, even

\footnotetext{
4 Basham 1976.
} 
thinkable had medicinal value. Somehow this medical system seemed so much more comprehensive and integrated than Western medicine-attending to individual ailments while curing more fundamental problems of the social order, operating in a world where healing was accomplished by way of the interconnectedness between ruler with ruled, environment and inhabitant, mind and body, cause and effect that exceeded the familiar territories of biology with which I was familiar. ${ }^{5}$

Even Basham had to keep his scepticism at bay, however. He wrote that the Vaidya's ideas about physiology were, for example, "by all modern standards thoroughly inaccurate," Still, he too, was able to look sideways at the question of efficacy, noting that these medicines and these medical systems, in these historic times, in some sense, still "worked". [...] they were and are "efficacious".

I would guess that many of us have been drawn to the sense of a "former glory" in the history of world medicines presented in and through IASTAM. The works bring with them the thoroughly modern dual sensibility of both progress and loss - the state of decline from the past found in the disappearance of traditional knowledge, the collapse of social infrastructures of healing, the rise of the kali yug, the rise of progress and science-technologically superior but highly specific in its profits. Today, it seems that Western medical supremacy easily displaces traditional knowledge in exchanges imposed by the inescapable imperatives of first colonialism and then postcolonial modernity. IASTAM emerged as part of the recuperative enterprise-recovering the treasures of these medical systems that seemed so embedded in the past yet were still available and relevant, yet still somehow needing to be "explained" or made sense of in "modern" terms or by "modern" standards.

I was reminded of the challenge of this undertaking when I sat with a young mother named Drolma in a tea shop in rural Medrogonkar, Tibet, a few years into our work on the safe motherhood project in Tibet. She told me about her six-month-old baby who had recently suffered from a case of "chinpa pap" ( mchin 'bab), "fallen liver." She told me her baby would have died were it not for the powerful "mirror treatment" of the famous Tibetan doctor, amchi Nyenrongshar, in Lhasa.

Fallen liver happens when a child has been frightened suddenly, Drolma explained to me. Her soul flees out of terror. It commonly afflicts babies who, as a result of this lost soul, get high fevers, coughing. They have difficulty breathing. Symptoms usually begin at night. In order to retrieve the soul, the Tibetan amchi must hold a small mirror (the back side of a brass ladle will do)

\footnotetext{
5 See also Marglin 1990.
} 
and place it up against the liver of the child. With burning incense making a pleasant aroma in the room, and inaudible incantations, he jerks the mirror inward and upward, lifting the liver while calling the soul to see itself in the mirror and re-enter the child's body.

Drolma's vernacular explanations of a well-known Tibetan medical treatment followed and revealed a Tibetan cosmology that becomes evident in particular in times of illness and healing, and one that is common among rural lay Tibetans. Mchin 'bab is a well-known condition described in the classical Tibetan medical text, Rgyud Bzhi. According to some Tibetan physicians, the 'fallen liver' disease is classified as either a hot or a cold disorder. ${ }^{6}$ Both these conditions cause the liver to 'sink' or 'fall' downwards a little which can be felt by an abdominal pressure check. Tibetans say the Chinese call this Gan Xia Chui and say it usually occurs in adults. If it is a hot disorder, the ensuing symptoms will entail a very high fever, loss of sleep, swollen forehead, and short breath. Even in the Tibetan doctors' office, the mirror treatment is considered extremely effective; and high fever can be cured quickly.

My Western physician colleague, Dr. Jennifer, sat in the teahouse with us that day in disbelief. "High fever, coughing, difficulty breathing," she said, "All signs of Acute Respiratory Infection". Without antibiotics, she said, a child like that will in most cases die. Drolma, not understanding the English that was just spoken, continued to insist "If we go to the Western (Chinese, phyi$l u$-outsider) hospital and take medicines for that problem, then our child will die". The amchi's treatment, she said, is the only cure. Dr. Jennifer continued to talk about the high rates of ARI in these rural areas, wondering how many babies died from the lack of antibiotics, concluding that "superstitions like this one about 'fallen liver' are deadly".

People choose to use one kind of healer over another for many different reasons, but almost always because they believe that one will be more efficacious than the other. But this doesn't mean that the healer chosen will be the most effective. Efficacy is a slippery concept. It often has as much to do with politics, economics, statistics and sentiment than it does with physical evidence. Franz Fanon, for instance, wrote in his Studies in a Dying Colonialism about Algeria just before independence, that sometimes rational medical decisions only make sense as political acts. He writes (speaking as an Algerian):

If I abandon what I am in the habit of doing when my wife coughs and I authorize the European doctor to give her injections; if I find myself literally insulted and told I am a savage because I have made scratches on the forehead of my son who has been complaining of a headache for three days; If I tell this insulter he is

\footnotetext{
${ }^{6}$ Dr. Mingkyi Tsomo of Lhasa offers this insight.
} 
right and I admit that I was wrong to make those scratches which custom has taught me to do-if I do all these things I am acting, from a strictly rational point of view, in a positive way. For as a matter of fact, my son has meningitis and it really has to be treated as a meningitis ought to be treated. But the colonial constellation is such that what should be the brotherly and tender insistence of one who wants only to help me is interpreted as a manifestation of the conqueror's arrogance and desire to humiliate.

Fanon tells us: "The colonized who resisted hospitalization did not do so on the basis of fear... The colonized not only refused to send the patient to the hospital, but he refused to send him to the hospital of the [...] conquerors"?

It would be hard to say that Drolma intended us to think that she would refuse antibiotics because of her status as a colonized subject, or that the sentiments of my American colleague should be equated with colonial power, but it would not be a far stretch to note that multiple rationales of efficacy were in play at the teahouse that day. When a mother fears the loss of her child's soul, and decides to trust only the Tibetan doctor with the act of safeguarding her progeny, one would want to remember that soul loss stems from many sources, and the possibility of reading collective loss of soul in Tibet under the regimes of modernization is a story yet to be told.

Efficacy returns here as a tricky and murky problem, in one instance feeling like "co-incidental" luck (when temporal frames are adjusted to help me get to a birthday party or a dying woman get a blessing) and in other instances feeling like a complex interweaving of bodily and therapeutic logics (that perhaps make Tibetan doctors more trustworthy than Chinese or Western doctors). Even if we rest, though, with an understanding of efficacy that entails more than simply biological measures (Levi-Strauss' symbolic healing, Victor Turner's social therapy), there is still the thorny matter of Drolma's living child - who, despite her rejection of antibiotics, managed to be cured by the amchi. Perhaps Drolma's child didn't have ARI, and perhaps Drolma's perception that all babies who have soul loss must have their souls returned is not a mistake-not a false perception of reality. Perhaps efficacy comes in many forms and in the moments of oblique insight where what looks like faith on the part of Drolma also becomes a kind of reason, and in the context of colonial oppressions and also in some sense, in the "skin" of Drolma and her child, this reasoning suddenly makes sense.

Encounters like this poke holes in our comfortable sense of efficacy, producing a surfeit of doubt on the one hand, in which we want to know: do the children really have respiratory infections and wouldn't antibiotics help?

\footnotetext{
7 Fanon 1978.
} 
Perhaps they are taken too late to the hospitals and so some of these babies do die? On the other hand, they also produce a desire to give certainty to this logic and this behavior, to find a logical reason that would tie the biological reality of a living baby to the ways that traditional healers are able to heal ARI by retrieving lost souls. Even if we recognize differences between vernacular and professional understandings of diseases and their treatment, such as when Tibetan medical treatment by an amchi for 'fallen liver' disease entails use of a mirror to 'fix' and 're-place' the liver properly in the abdomen of a child and thereby reduce the fever is not exactly the same as a villager's belief that retrieving lost souls is the only way to cure a child with fallen liver. For Tibetan patients like Drolma understanding that the amchis treatment works means blurring the perhaps spurious distinctions between ritual 'magic' and the physical manipulations of livers that help reduce fevers. People need explanations that match their own cultural and cosmological systems. Perhaps treatment by antibiotics is also partly effective for this reason.

The subtle and layered meanings that are visible in the events of sickness and healing are seldom overlooked by those studying Asian medicine-in some sense, reading such events as simultaneous enactments of larger social phenomena is a methodological achievement of our field. I think particularly of the work not just of Charles Leslie, but of so many who have followed him: Judy Farquhar, Elisabeth Hsu, Geoffrey Samuel and Volker Scheid, Vivienne Lo, Paul Unschuld in China and Tibet, Robert Desjarlais, Frédérique Marglin, Stacy Leigh Pigg, Jean Langford, Ashis Nandy, Joseph Alter in India and Nepal (as well as many others whose work on Asian medical concepts help shape this field, Charlotte Furth, Margaret Lock, Francesca Bray, Arthur Kleinman). In their analyses, I am always indirectly returned to the fact that efficacy, rather than being objectively fixed in measureable and visible changes in the body, is something of a floating signifier for other underlying or overlying things. By this, I mean something like what Lévi-Strauss noted as a certain kind of productivity in distinguishing between signifiers and signified and in recognizing how the free floating quality of some words could, while meaning different things to different people, still generate potent symbolic effects, structural rules by which people organized themselves and their consciousness. ${ }^{8}$ For others who followed after, the signifier was not a means of uncovering rules of human nature, but a moment's resting point in the arbitrary movement to new sites of signification. The sign inaugurates a perpetual sequence of referencing, creating indices of presence and absence, investment and profit,

8 Derrida took this notion further to critique Lévi-Strauss's commitment to the authenticity of the sign (Derrida 1976). 
perspective and experience. This understanding of a floating signifier in "free play" might help explicate efficacy in the way I am thinking of it here. It allows us to read efficacy as unattached to a singular fixed biological ground in any essential way, but still endlessly referential as it moves to other signifiers that pull with them new kinds of evidence. Evidence here is made visible or invisible, present or absent, negotiated into being or erased entirely on the ground of the physical in and through quite cultural lenses.

Here, the point is not to note that biology is local, ${ }^{9}$ but to note that biology is a consequence of lots of other things that are political, social, ideological, practical and emotional.

Efficacy moves like this, from resting place to resting place, sometimes signifying a commitment to nationalism, resistance, or to family commitments, and other times signifying biological states but taken as a whole-in constant motion. The more it moves, the more one realizes that it becomes less important to define what efficacy is as a measureable condition than it is to see it as more or less a means of authorizing something more profound in medicine. Efficacy authorizes the movement from episteme to practice. By episteme, I mean not "theory" so much as foundational or orienting rubric, fundamental tenets that are taken as givens, like gravity, germ theory or karma, the relation of elements, notions of pathogenesis and progression of diseases in the body. Following Farquhar's insights, epistemic truths arise at socio-historical moments and define a universe and the relations between people and things therein. Practice refers to the implementation of these foundational rubrics in the context of individual persons. Efficacy happens at the intersection of episteme and practice, where person and sociological context blur. This intersection forms the essence, the heart, of efficacy.

I choose the term "heart" deliberately here as synecdoche, in reference to the fact that many Asian medical systems (in Leslie's sense of System) take the heart as the seat of consciousness, not the brain. Perception arises from the heart, as does emotional sensibility. In Tibetan, the sems (one's perceptive mind), and one's conciousness (rnam shes) are part and parcel of the organ that generates (or limits) emotional commitment and motivation. One's ability to reason, to make sense, and to feel, are all tied up in this blood-pumping organ, connecting rationality to emotional intention to physiology. This epistemic fact matters quite a bit in the journey from sign to signifier to sign but also from sign to sign in the constitution of efficacy.

In order to see this movement in action, let's return for a moment to Tibet and listen in on a conversation I had with Dr. Dorje at the clinical research

\footnotetext{
${ }^{9}$ Following Margaret Lock and Vinh-Kim Nguyen's recent work (Lock and Nguyen 2010).
} 
division of the Qinghai Provincial Tibetan Medical Research Institute in Xining, Eastern Tibet. Dr. Dorje specialized in liver diseases. In the context of a rapidly modernizing medical system, Tibetan doctors are continually faced with the dual challenge of establishing the efficacy of Tibetan medicine using biomedical research standards and simultaneously preserving Tibetan medical traditions by showing their contemporary relevance. This should be read as an effort to protect traditional medicine from the scientific colonizations of biomedicine while also participating in new regimes of biocapital found in successful marketing and sales of traditional medicines worldwide. Dr. Dorje believed that traditional Tibetan medicines offered important curative and therapeutic options for people with liver diseases.

One of the goals of the research division, he said, was to develop a new clinical research platform for the study of Tibetan therapies using a combination of integrated biomedical and Tibetan approaches. The government required use of laboratory diagnostics like CT scans, MRIs and blood tests in the hospital. Moreover, the government was pushing these technologies as the foundation for clinical research, noting that in order for research results to be recognized as valid, they would have to follow some biomedical protocols. At the same time, medicines that had been used by Tibetan doctors to help people with liver problems were thought to be better at improving the quality of liver function and to provide a repertoire of interventions that were virtually unknown in Western approaches. The problem was, it was difficult to use biomedical diagnostic techniques like CT scans and blood tests as substitutes for traditional methods of diagnosis such as questioning, tongue and urine analysis and pulse reading.

Already, the pharmaceutical research division had developed a large repertoire of studies on toxicity, production techniques, and active ingredients using animals like mice and rabbits. These were primarily required for meeting GMP (Good Medical Practices) standards in China, which were in turn based on GMP international standards exported from the United States. Doing research on the manufacture of medicines was easy, but clinical research efforts, he noted, posed problems.

Once you were doing research on real patients, it was impossible not to use traditional indicators for diagnosis and treatment, including questioning, palpating, tongue, urine and pulse analysis. These sometimes created confusion when put alongside Western laboratory results. The trouble was figuring out how to determine which outcomes should be used to measure efficacy. Dr. Dorje's confusion over how to link practice with episteme stems from the fact that multiple technologies were available. Assigning truth value to the evidence they produced was, for him, often more a matter of the clinician's 
particular commitments rather than the "factual" representations that emerged from the technologies themselves. Dr. Dorje said this was particularly true for the case of patients with liver diseases. "We are always facing this kind of conflict," he said:

Some liver diseases, especially chin dran [which translates roughly as "liver cancer" or "liver tumor"]. We have these kinds of patients. If, after you give them treatment, you take the patient's pulse, you read his pulse and urine for symptoms and his pulse is normal. Before it was very fast and hard, and now these symptoms have disappeared. You can even see that the patient looks better. He is more confident, and he looks happy, and there is no pain and the symptoms have disappeared. Even his urine is normal. But if you take CT scans, or if you take MRI, then you can still see tumors. It does not appear to be smaller.

I stop to ask: "Is this patient cured or not?". I see his point that different technologies will give you different results and it is difficult to say which one is the more reliable. Before I get an answer, he tells me,

We cannot tell the patient that he has a tumor in his liver that has not gotten smaller. In my experience if you tell the patient, for example, you have a tumor in your liver and it did not get small,' then the patient suddenly becomes more sick.

I had a patient like this two years ago. This patient was 26 years old. He took a CT scan at the Chinese army hospital and he was diagnosed with liver cancer. $\mathrm{He}$ took another CT scan from our hospital and was diagnosed with cancer again. But the patient is illiterate, you know? Even when you say to him, "You have cancer", he wouldn't understand what this means. He is very young. Also, he doesn't have many symptoms. He looks like a very normal person. If you check his pulse, he is normal. He only had headaches occasionally, but not serious, and occasional nausea. Sometimes his digestion was not good. But he didn't want to be an inpatient because he did not feel very sick, so we treated him as an outpatient... for two years. We took another CT scan recently and apparently he still has cancer, but his tumor is getting smaller, using only Tibetan medicine. Normally in Western medicine, they would say that if you have cancer in your liver like this, you will only live three months, but this patient is already three years. The problem is that we were not able to do a biopsy on this patient. We don't know if he really has cancer.

Dr. Dorje's own ambivalence about the "truth" value of diagnostic indicators is clear. Does the CT Scan tell the truth about efficacy but fail to account for the other factors that impinge on outcomes? The patient has a growth, but is it "cancer" in the Western diagnostic sense? Maybe the CT scan can be misread, even if it is telling the "truth" about a growth. There is reason to doubt the truth value of urine and pulse indicators because they take the CT scan seriously-as offering competing truth. After all, the CT scan suggests that 
Tibetan medicine did work to reduce the tumor size. So sometimes the scan can be trusted and sometimes it cannot.

One thing was certain, Dr. Dorje was not skilled in the recovery of lost souls that came with the problem of what Drolma had told us was "fallen liver," mchin 'bab. Trained by the generation of Tibetan doctors who had been forced to reject causal explanations of things like spirit attack and soul loss as "deadly superstition" — as dangerous not only to patients but also to socialist progress itself-Dr. Dorje was unfamiliar with the old repertoire of mirror incantations and callings of the soul. In old times, shamans did these things, searching for lost souls, afflicting deities and demons. They called it mogyo"hunting" - as the Sherpas say, when the shaman went into his trance state, leaving his body temporarily in order to track down the real cause of disease lurking in the unseen world of spirit beings, like a hawk fluttering above a field hunting for its prey. These practices of healing were, for Dr. Dorje, things of the past; rural villagers and folk practitioners knew of them, but for him they were no more than inaccurate falsities, naïve explanations for sickness and its causes, attributable primarily to lack of education. As an expert in liver diseases, however, Dr. Dorje had to undertake a fair amount of "hunting" of his own, tracking down the correct diagnosis like a hawk in search of its prey. With the arrival of Western scientific repertoires, technologies and cosmologies, things like growths, pains, obstructions, and poisoning had to be named as causes of diseases like cancer, cirrhosis, hepatitis. New repertoires for old problems did not make diagnosis easier nor did it make the task of locating and tracing efficacy easier. Now, in addition to searching for the right diagnosis, he now had to do his own sort of hunting for efficacy as well.

By turning to the role of the patient's perception and confidence, Dr. Dorje diverts us from the unresolvable problem of conflicting diagnostic techniques and competing indicators of therapeutic success, and from his own uneasiness with the idea that CT scans can't always be trusted to tell the truth. Instead, he turns away from questions of technology and returns with confidence to his point, which is that if patients know they are being treated well, he tells me, if "they know 'I can defeat the disease and the doctor can help me,' this is the important thing". This, for him, was the most important therapeutic factor in deciphering whether or not a patient could be cured.

What would be readily dismissed as placebo, that is-evidence of ineffectiveness - in Western medicine, is for the Tibetan doctor a critical feature of treatment without which efficacy is impossible. Perception in the truest sense enables the patient himself to bridge the gap between contradictory readings of technological data. It provides the "leap of faith" that enables healing to occur for this doctor, not because faith requires a transcendence of empirical 
verifications in the body but because it provides a different kind of basis for such bodily empirical facts.

Keeping in mind that emotional perception for Tibetans is also a function of the heart, not the brain, helps to explain this. If the heart is seeing and feeling, then it makes sense that having confidence in one's healer will have a direct effect on changing bodily states. Perception changes the heart rate, which affects digestive processes of absorption and excretion, which in turn affect the ability for the tissues to function, to be lubricated, to have energy for movement, vitality and strength. Such heart processes have the potential to do things like eliminate the blockages that have now formed into a hard mass in the liver or to help the liver function better to filter and nourish the blood. If the blood collects and continues to collect until the reasons for the blockage are removed, it will look like a tumor. If the liver is not fully functional, the blood gets weaker and fails to nourish other organs and tissues. Here, perception plays an intimate role in ensuring that thoughts and emotions are involved in heart function, changing the flow of blood and conditioning its quality. It recalls the adage: "If your heart is not in it, it won't work" or, in this case, you won't get well.

Dr. Dorje's sense of efficacy in the complex and highly integrated world of Tibetan medicine in Tibet is one that has to move in and out of different kinds of reasoning. He is simultaneously focused on the hope that there could be "objective" measures in things like CT scans and MRIs that show effectiveness across cultures, no matter what medicines are used. At the same time, he recognizes the fact that such definitive measures don't really exist in ways that accommodate all the different techniques used to measure physical outcomes that are available to him. To some extent the truths about what really works have to be produced in and through careful practices of both producing and concealing evidence. All diagnostic techniques measure something, but they don't always tell the same truths. Shigehisa Kuriyama reminds us that the act of seeing is conditioned and contingent on the layered and embedded ways in which the body, the empirical world, are already configured as cultural givens. ${ }^{10}$ The physical body is not only experienced but also in some sense only exists by way of these different modes of seeing. Dr. Dorje knows this intuitively when he tells me: "Some doctors ignore the Western lab results, because they know from Tibetan measures, indicators, that it is ok. The disease is getting better".

How one reads the body, or how one sees it by way of different diagnostic and outcome measuring technologies, matters. Once this is recognized, then the body, and the logic by which one feels one can know the body, must follow

${ }^{10}$ Kuriyama 2002. 
suit. The calculus by which the body is known is the route by which it becomes treatable, and this can shift or at least be made murky, requiring a sort of hunting expedition. Efficacy here is a moving target. The healer must account for the subtle changes that can be made in perception, not just in the delivery of medicines and diagnostic techniques. The healer must know how to move between and include/exclude or blur the repertoire of indicators that tell him or her that a patient still needs medicine or that the patient is cured. A patient who is by all Tibetan measures improving with treatment by Tibetan medicines, may still generate laboratory results that say he is still sick. One has to manage this information so as not to disturb the patient's heart. The patient must perceive that they are getting better. But one must also deal with the thorny presence of lab results. Since they could be seen as pathogenic, a good doctor might have to ignore them, especially if there is ample evidence that point to contrary conclusions. But sometimes lab results affirm the effectiveness of Tibetan medicines and so being skeptical of these results can be problematic. Entering the clinical space obliquely and in ways that blur epistemic frames, Dr. Dorje tells me that the patient who is definitely better by Tibetan indicators, and who wants to leave the hospital because he feels better, but has lab results that say he is still sick, is not uncommon. He says,

This kind of patient, we usually recommend that they keep on their food and behavior treatment. For example, some food is not good for liver function, alcohol and garlic and spicy and those very cold foods. They should not eat these. And for behavior, they should not work too hard. It is not good. Take a rest, relax and keep to the food and behavior that the doctor recommends. If they feel uncomfortable again, they should come back for medicines. But, the problem is if you just keep giving medicines...you know, most liver medicines-medicines for liver problems - are cold (phyilu) according to Tibetan medical classification. So, if you take these medicines indefinitely, they will cause other problems for your kidney and stomach. So, we focus on diet and behavior.

Here, Tibetan medicines work and skepticism is directionally reversed. Tibetan medicines are efficacious enough to show improvement in outcome, as measured in the urine and pulse. In fact, the medicines are so effective, if they are given for too long, they can create other imbalances. This is known by Tibetan doctors not by having scientific skepticism about their own medicine but by engaging in a delicate dance of believing and disbelieving the CT scan. The CT scan tells the truth but not the whole story. It doesn't undermine the effectiveness of Tibetan medicine but it does not lie. It merely shifts the therapeutic frame, telling the physician that in order to stay well, the patient needs to manage his health through diet and behavior regardless of what the scan says.

The thing is, the prescription of changing diet and behavior presupposes an epistemic connection between perception and motivation. Motivation follows 
after perception of the need to alter what one eats or does. In Tibetan medicine, these phenomena are possible through the energy of wind, rlung, the humor aroused by a primordial presence of karmic desire. Wind is the vital energy or "poison" that manifests in the body and is responsible for all movement, of breath, blood, fluids, thoughts. The wind bridges the perceptual and emotional to the physiological. Thought rides on the wind, built by karma, cognition, sense awareness. Epistemic knowledge emerges in the clinical model giving substance and validity to claims of efficacy that can't be seen on the CT scan and sometimes requires the need to ignore entirely what the CT Scan says because a patient's perception matters in physical ways.

In the end, Dr. Dorje's reasoning reveals a continuum on which efficacy arises and is negotiated, crossing epistemes and practices. Evidence gets read one way sometimes and other ways other times. Dr. Dorje was troubled by the sense of closure he had witnessed among those who relied only on biomedical indicators. He attended a conference in Shanghai that year with some traditional Chinese and Western doctors. He told me,

One of the Western doctors from a Shanghai hospital gave an example of a case. He treated a patient and finally, in the end the patient was dead, but before he was dead, they checked his liver. The cancer got smaller, but the patient is dead. When they discussed the case, the cause of death, the doctors said "the treatment is successful," because the tumour was reduced, right? But at the meeting, many traditional Chinese doctors and many other doctors said that according to traditional Chinese and Tibetan medicine, this is not a success, because the patient is dead. Yes. It's true that you can reduce the tumours. But the patient is dead. So, how can you measure that as success? Western doctors said, in their discussion of the cause of death, they said, "Oh, this treatment is a success and this medicine is effective".

It wasn't hard to understand Dr. Dorje's sense of frustration here not over what constituted efficacy, but rather about what should be able to stand in for efficacy when the patient dies. For whom and to what end is medical effectiveness directed? Every medical system uses a variety of measures of efficacy and they are always context-dependent. Sometimes, understanding the mechanism that produces death is worth exploring, even if you can't keep the patient alive. Dr. Dorje understood that biomedicine frequently uses mortality as a measure of efficacy, but in its global science pharmaceutically-driven contours, it becomes possible to separate the death of the patient from the effectiveness of the drugs the patient took, and this required "moving" his own commitments to efficacy significantly, even to the point of being uncomfortable. Dr. Dorje surely also understood that had the patient taken the drug sooner, he might have lived, but his concern seemed to be that in an accounting system that logs success of the drug over survival of the patient, one might forget to keep the two connected. 
Postcolonial scholars Ashis Nandy, Shiv Visvanathan and even Adriana Petryna have pointed to the vivisectionist imperatives lodged within Western science here. ${ }^{11}$ Knowledge sometimes comes as a trade-off, some patients die but for the good of learning what works to keep others alive. Here, too, one could read synecdoche-in the reductionistic measures that generate statistical robustness but forget the individual, in the technologies that erase techniques and anatomies that cannot be seen, and in the prioritizing of the pharmaceutical over those intangible and non-profitable practices of healing. But I would rather focus on the illustrative nature of Dr. Dorje's insight: efficacy is more of a floating signifier than a defined biological reality, sometimes signifying the pharmaceutical imperative (a drug must show effects even if we can't really be sure it will keep patients alive) and other times signifying the survival of a culture - a way of knowing/seeing/being in the world (again, even if we can't prove that it will keep patients alive).

This was more obvious in a study that I was involved with at Lhasa's Mentsikhang (Tibetan Medicine and Astrology Institute/hospital) from 2000 to 2005. We were trying to compare the effectiveness of a traditional medicine Zhi Byed Chu Cig (ZB11) with Misoprostal (a biomedical drug) in preventing postpartum hemorrhage in delivering women. I shared hope with my Tibetan colleagues that the study would show that ZB11 was effective. This would help to justify its continued production and possibly encourage its distribution and use in rural clinics where many women die from hemorrhage during delivery. Using a Tibetan medicine was important for the doctors at the Mentsikhang, and we knew that rural women tended to prefer Tibetan medicine, especially with regard to obstetric events. It was without a doubt part of a larger effort on the part of the Mentsikhang to desires for preservation and revitalization of Tibetan culture more widely.

Preparation for the study took two years, involved establishing Internal Review Boards in Lhasa that met the US Government's Office of Health Research Projects standards for foreign IRBs, and required massive efforts and translating between protocols found in the Tibetan canon in order to construct a clinical trial that looked at least somewhat consistent with treatments familiar to the Tibetan repertoire. ${ }^{12}$ In the end, the research used a randomized controlled double blind model comparing the two drugs, rather than a study that compared use of the Tibetan medicine with no medicine. It was also a limited comparison in that it looked only at the two drugs rather than comparing the full course of Tibetan interventions that would normally be used.

Results of the study showed that Misoprostol was better at preventing post-

11 Nandy and Visvanathan 1990; Petryna 2009.

12 Much of the work on this part of the project was done by Dr. Sienna Craig and Dr. Mingkyi Tsomo in Lhasa. 
partum hemorrhage during labor than ZB11. Mortality rates were not different: none of the patients died. Misoprostol was associated with higher rates of fever and other side effects. Both medicines worked to reduce blood loss after delivery. But the results were published as a "negative study" showing that Tibetan Medicine did not work as well as Western medicine. The Western medical team was disappointed. The research results were only published in a less prestigious journal of midwifery and women's health. Had it been a positive study, showing positive outcomes, it would have been published in a more prestigious journal, like the Lancet, they said. In the final reports distributed throughout the Lhasa Health Bureau, one outcome became the focus: Misoprostol worked better than ZB11 even though both reduced blood loss. Policies for distributing Misoprostol to rural clinics in the Lhasa Prefecture were put in motion, displacing use of traditional Tibetan medicine in this context.

Of course, the swift implementation of this evidence-based medicine (going from clinical study to policy change) was only itself a result of the overinvestment made by the research team in the larger question of how to take care of rural delivering women. In order to do the study at all, we had to develop training courses that would teach our Tibetan counterparts how to do research in this quite culturally-specific way, using statistical reasoning, randomization, informed consent and controlled comparison. It also entailed ignoring local concepts of ethicality (in the problem of patient perceptions of risk, impact of doctor's demeanor, or unspecified notions of karmic causality) in favor of verified practices of consent-making through processes of obtaining written and verbal agreement and "vetted" IRB procedures. With the large and cumbersome research apparatus that was needed to obtain good quality objective data, it was impossible in the end to allow for much flexibility on the part of treatment, patient variability, or Tibetan measures of outcome. It was as if there was no way to stop the inertial movement that the study itself set in motion, in which eliminating use of specific Tibetan knowledge was not due to failure of the Tibetan medicine but simply an artifact of the research design.

The eddies into which traditional medical practices get pulled in the search for efficacy are many, and sometimes they rely on a specific notions of efficacy—or rather on the notion that efficacy is specific and fixed. Misoprostol worked "better." The evidence is there. The fact that the entire discussion of the limitations of the clinical trial model, including the exclusion of companion medicines for the sake of quality assurance and standardization, was foreclosed early on did not make it into the publications. The other benefits of using ZB11 over Misoprostol, such as cost, support for traditional medicine, and reduced side effects, were never debated as part of the design of the clinical 
trial. What Dr. Dorje and others would have us consider is the possibility that sometimes evidence needs to be drawn from a wider catchment area. Sometimes "evidence" needs to include things like the place of medicine in national consciousness, the full scope of Tibetan diagnostic and intervention repertoires, and the fact that ZB11 works differently but with fewer side effects, and that both medicines work effectively to keep patients alive. That is, Misoprostol worked better in the study, but if the clinical trial had been able to include these other variables, then Tibetan medicine might have been shown to be the better medicine to use for delivering women in rural Tibet. The fact that science travels sometimes enables a critical inquiry into the routes by which efficacy has the opportunity to get fixed in specific outcomes. Sometimes these routes reveal how institutional relationships become the means by which efficacy is in the end tied to new forms of governance.

\section{Conclusion}

Medical systems arise and flourish, decline and or change in relation to historical, anthropological, sociological facts. Moving outward from bodies, to larger historically situated understandings of the ways that medicine is both product of its cultural milieu and responsive to it should be at the heart of discussions of medical efficacy. Knowledge and epistemology are always formed in crucible of socio-political ferment, as is the ability for its practices to be efficacious. Social scientists have long embraced the possibility of reading efficacy in terms of social, cultural, or psychological registers, but when it comes to recognizing how these kinds of practices also blur with, impact, or condition healing in a biological sense, there is less agreement. In fact, there is a lot of skepticism. When it comes to measurables and to accounting for things like tumour growth, respiratory infections, hemorrhage during delivery, it feels safer somehow to stick to things like laboratory tests, ultrasound images, and statistical significance. It takes an active effort not to let them slip into the place of default truth in matters of efficacy. Despite the highly contested and ambivalent nature of these technologies (as shown in the research on them within places like the United States, as Annemarie Mol and Deborah Gordon and others have shown), ${ }^{13}$ the expectation is that they can offer more undisputable evidence when they travel. But they don't. As they travel, efficacy also becomes mobile and debated through new indices of truth, evidence and visibility.

${ }_{13}$ Mol 2003; Gordon 1988. 
For certain, we are no longer able to use simple notions of relativism as a way to make sense of Asian medical systems. That strand of reasoning dissolves when relativism fails to bridge the gap between signifier and signified, when efficacy starts to look like a free floating option and the measures of validity and truth in the "evidence" are no longer straddled across a bridge of cultural difference. Nor are we able to claim colonial distance as a way of explaining the location of efficacy because outsider-insider distance is no longer situated on the borders between history and the contemporary. Epistemological assumptions blur as readily in the CT scan as they do in the recognition of the wind's role in changing one's heart rate. Syncretism and hybridity are also made problematic in this place, since they require an intactness or stable place of fusion within an epistemological frame. Rather, efficacy gets fixed in a wide variety of indicators as the intimate connection between multiple frames of episteme and practice. Efficacy floats above its fixed references in the empirical world; but it gets pinned down at specific moments and in specific places as a result of biology, emotion, cultural and political forces, or even the search for a cure for the collective soul loss of a nation. Tracking efficacy as it travels from place to place sometimes entails witnessing its shifts from sign to sign to sign, dragging along biologies in the wake of representations that are tethered to new and ever-changing concerns about robustness, validity, cultural preservation and, in some cases, patient mortality.

So where does this leave us? Things get murky in the hunt for efficacy. Tracking whom and to what end efficacy is directed matters, not just for the social analyst, but for the healer as well. Incommensurability between the fears of Tibetan mothers like Drolma and the antibiotic imperatives of Dr. Jennifer are not easily bridged in view of the living evidence of children who are healed by "mirror" cures. Turning to the local healer to bridge this gap does little to streamline the hunt. Dismissing spirit cures for the sake of CT scans, as Dr. Dorje has done, does little to create a stable resting place for efficacy; there is no place that rests comfortably on singular and singularly certain empirical ground. Dr. Dorje's daily walk through the world of conflicting evidence does not make it impossible for him to find certain results, but in order to do so he has to find clever ways of reading through results obliquely, not letting truth sit comfortably in bounded epistemes that fix biology in specific and limited ways.

I want to end, then, not on a point of comfortable completion, but with a question: if efficacy is more of a floating signifier, what remains as an empirical ground for setting the boundaries around deciphering healing? Dorje's insights about the risks of adhering to an episteme in which you could say the medicine might work even if the patient dies, travels and lures us into a place of 
certainty about one boundary at least. He would have us consider the ethical imperatives of clinical trials - that is, that medical research should always consider the problem of individual outcome and not just what happens to the organ or the biological effects of drugs in deciphering efficacy. This feels like a comfortable boundary. Let's not forget that the ultimate purpose is to "keep patients" alive. But then I am reminded of Rosemary. Dr. Dorje's concern was with the mistaken assumption of efficacy: saying that the medicine worked when the patient still dies is to him an ethical failure. But Rosemary's incidental tagging along on our audience with Bruce that day ended up being efficacious in a way that once again asks us to read even this certainty with a sideways gaze. Rosemary died within the year after that fateful audience with Bruce when she was momentarily moved in ways we couldn't explain. She reminds us now that, even here, sometimes the patient will die, but the medicine may just work.

\section{References}

Basham, A.L. 1976, 'The Practice of Medicine in Ancient and Medieval India,' in Charles Leslie (ed.), Asian Medical Systems: A Comparative Study, Berkeley: University of California Press, $18-43$.

Derrida, J. 1976, Of Grammatology, translated by G.C. Spivak. Baltimore: Johns Hopkins University Press.

Fanon, F. 1978, 'Medicine and Colonialism,' reproduced in J. Ehrenreich (ed.) The Cultural Crisis of Modern Medicine, New York: Monthly Review Press, 229-251.

Farquhar, J. 1987, 'Problems of Knowledge in Contemporary Chinese Medical Discourse,' Social Science and Medicine 24, no. 12: 1013-21.

Gordon, D. 1988, 'Tenacious Assumptions in Western Medicine,' in M. Lock and D. Gordon (eds.), Biomedicine Examined, London: Kluwer Academic Publishers, 19-56.

Kuriyama, S. 2002, The Expressiveness of the Body: The Divergence of Greek and Chinese Medicine. New York: Zone Books.

Lock, M. and Vinh-Kim Nguyen. 2010. An Anthropology of Biomedicine. New York: WileyBlackwell.

Marglin, F. 1990, 'Smallpox in Two Systems of Knowledge,' in F. Apffel Marglin and S.A. Marglin (eds.), Dominating Knowledge: Development, Culture and Resistance, Oxford: Clarendon Press, 102-144.

Mol, A. 2003, The Body Multiple: Ontology of Medical Practice, Durham, NC: Duke University Press.

Nandy, A. and S. Visvanathan. 1990, 'Modern Medicine and its Non-Modern Critics: A Study in Discourse,' in F. Apffel Marglin and S.A. Marglin (eds.), Dominating Knowledge: Development, Culture and Resistance, Oxford: Clarendon Press, 145-185.

Petryna, A. 2009, When Experiments Travel: Clinical Trials and the Global Search for Human Subjects, Princeton: Princeton University Press. 